УДК 378.147

\title{
РОЛЬ МЕЖДИСЦИПЛИНАРНЫХ СВЯЗЕЙ В СОВРЕМЕННОМ ВУЗОВСКОМ ОБРАЗОВАНИИ
}

Попова Нина Евгеньевна к.П.н., доцент

Екатеринбургская академия современного искусства

Аннотация: В монографии раскрывается значение междисциплинарных связей при формировании компетенций обучающихся на основе ФГОС ВО 3++. Алгоритм внедрения модели рассматривается через идею, цель и задачи, а также дается описание типам, функциям, принципам, видам междисциплинарных связей. Анализируются формы, методы, приемы и технологии внедрения междисциплинарных связей. Особое внимание обращается на модель реализации содержания междисциплинарных связей, структуру, способы планирования, а также процесс управления и установления эффективности внедрения междисциплинарных связей в образовательный процесс.

Ключевые слова: междисциплинарные связи; типы, функции, принципы, виды связей; формы, методы, приёмы, технологии реализации связей; модель реализации междисциплинарных связей.

\section{THE ROLE OF INTERDISCIPLINARY LINKAGES IN MODERN UNIVERSITY EDUCATION}

\section{Popova Nina Evgenievna}

\begin{abstract}
The monograph reveals the importance of interdisciplinary ties in the formation of the competencies of students based on GEF VO $3++$. The model implementation algorithm is considered through idea, goal and tasks, as well as a description of types, functions, principles, types of interdisciplinary connections. Forms, methods, techniques and technologies of introduction of interdisciplinary connections are analyzed. Particular attention is paid to the model for implementing the content of interdisciplinary links, the structure, methods of planning, as well as
\end{abstract}


the process of managing and establishing the effectiveness of introducing interdisciplinary links into the educational process.

Key words: interdisciplinary links; Types, functions, principles, types of links forms, methods, techniques, technologies for implementing connections; a model for implementing interdisciplinary linkages.

В настоящее время каждая наука расширяет свой информационный потенциал. Однако увеличивающийся объем информации по каждой науке не должен превышать объем годовой нагрузки обучающихся вузов. Как сделать так, чтобы увеличить поток информации для обучающихся при реализации ФГОС ВО 3++ [1], но при этом соблюсти нормы СаНПиН.

Выход есть. Необходимо перестроить учебный процесс и включить в него процесс междисциплинарных связей. Рассмотрим проблему междисциплинарных связей для реализации ФГОС $3++$ на занятиях в современном вузовском образовании.

Лекиия в вузе с междисииплинарными связями - это изучение отдельной дисциплины путем использования содержания других дисииплин на основе интеграции смыслового поля для передачи информации особыми формами, методами и приемами, способствующими реализации ФГОС ВО $3++$ u формирующими компетенции обучающихся [определение наше - Н.Попова].

Для подтверждения состоятельности данного определения, проблему внедрения междисциплинарных связей (далее - МДС) в вузе будем рассматривать с системных позиций на основе алгоритма, предложенного Гурьевым А.И., Усовой А.И. и др.) [2]: 1. Идея, цель, задачи $\square$ 2. Теоретическое исследование междисциплинарных связей $\square \quad 3$. Вариативные междисциплинарные формы, методы и приемы обучения $\square$ 4. Модель содержания образования с МДС $\square$. Модель организационно-управленческого процесса с МДС $\square$ 6. Модель практической реализации образовательного процесса с МДС $\square$ 7. Модель результативности образовательного процесса с МДС.

Дадим комментарии к предложенному алгоритму.

\section{1.Идея, цель и задачи внедрения междисциплинарных связей}

Идея организации учебного процесса на основе внедрения междисциплинарных связей (МДС) заключается в том, чтобы: 
1) использовать современные педагогические и информационные технологии для оптимизации учебного процесса;

2) активизировать мыслительные способности обучающихся;

3) создавать условия интеграции знаний, получаемых на различных дисциплинах, для формирования профессиональных компетенций.

Цель внедрения МДС: формирование концептуального мышления обучающихся на основе генерации системных знаний по изучаемым дисциплинам и умения устанавливать всесторонние связи между явлениями, понятиями, теориями, научными картинами мира, изучаемыми разными дисциплинами одного модуля, а иногда и несколькими модулями ФГОС ВО $3++$.

Цель внедрения МДС может быть достигнута при решении задач.

Задачи внедрения МДС:

1. Углубление знаний обучающихся по смежным дисциплинам (предметная задача).

2. Закрепление признаков, понятий, теорий, законов, правил, формируемых в единстве при изучении различных дисциплин учебного плана (интегративно-поисковая задача).

3. Предварительная подготовка обучающихся к усвоению отдельных разделов смежной дисциплины и выработка нестандартного решения комплексной проблемы (интегративно-творческая задача).

Достижение цели и задач междисциплинарного обучения необходимо начать с исследования теоретических основ.

\section{2.Теоретическое исследование междисциплинарных связей}

Междисциплинарные связи в вузовском обучении можно рассматривать в широком и узком значении.

Широкое значение МДС - это принцип дидактики, на основе которого происходит координация и систематизация материала дисциплин учебного плана, что позволяет в комплексе формировать компетенции обучающихся по ФГОС ВО 3++.

Узкое значение МДС - принцип дидактики, интегрирующий знания по одной дисциплине и выступающий одновременно средством объединения содержания нескольких дисциплин в систему, что позволяет расширить информационные потоки дисциплины без потери ее основного содержания. 
Реализация вузовского содержания дисциплин строится на теории о типах междисциплинарных связей.

Разделяя мнение В.С.Кукушина [3], считаем, что для формирования системного знания обучающихся и разработки лекций с МДС следует учитывать типь связей:

1. Учебные междисциплинарные связи осуществляются, когда знания по одной дисциплине становятся основанием для изучения другой дисциплины. Для реализации учебных МДС определяется тезаурус дисциплины, устанавливается связь с другими дисциплинами, разрабатывается рабочая программа дисциплины с использованием межпредметных связей, продумываются задания для контроля знаний обучающихся по нескольким дисциплинам.

2. Исследовательские междисциплинарные связи проблемного характера.

Решение исследовательской междисциплинарной проблемы возможно, если:

- определяются основные методы изучения дисциплины;

- определяются дисциплины с похожими методами изучения;

- определяются специфические методы изучения дисциплин, необходимых для междисциплинарных связей;

- устанавливается взаимосвязь основных и специфических методов изучения дисциплины;

- разрабатывается рабочая учебная программа дисциплины для обучения с применением интегрированных методов обучения;

- создается пакет заданий итогового контроля по дисциплине с применением междисциплинарных связей.

3. Ментальные опосредованные связи.

Реализация этих связей устанавливается на основе сопоставления рубрикатора компетенции, индикатора достижения компетенции и распределения индикаторов достижения по базовым учебным дисциплинам. Пример ментально-опосредованных связей представлен в таблице 1. 
Таблица 1

Пример ментально-опосредованных связей при реализации ФГОС ВО 3++

\begin{tabular}{|c|c|c|c|}
\hline \multicolumn{4}{|c|}{$\begin{array}{c}\text { Компетенция ФГОС ВО 3++: УК-1 Способен осуществлять поиск, критический анализ и синтез } \\
\text { информации, применять системный подход для решения поставленных задач }\end{array}$} \\
\hline $\begin{array}{l}\text { Рубрикатор } \\
\text { компетенций, } \\
\text { индикаторов }\end{array}$ & $\begin{array}{l}\text { Индикаторы } \\
\text { достижения } \\
\text { компетенций }\end{array}$ & $\begin{array}{l}\text { Распределение } \\
\text { индикаторов достижения } \\
\text { компетенций по } \\
\text { базовым учебным } \\
\text { дисциплинам }\end{array}$ & $\begin{array}{l}\text { Ресурсная база компетенции УК-1 } \\
\text { (дескрипторы компетенции) }\end{array}$ \\
\hline $\begin{array}{l}\text { УК-1.1. } \\
\text { Описание } \\
\text { сути } \\
\text { поставленной } \\
\text { задачи, } \\
\text { выявление ее } \\
\text { составляющих } \\
\text { и связей } \\
\text { между ними }\end{array}$ & $\begin{array}{l}\text { УК-1.1. } \\
\text { Формулирует и } \\
\text { анализирует } \\
\text { задачу, } \\
\text { выделяя ее } \\
\text { базовые } \\
\text { составляющие } \\
\text { и определяя } \\
\text { связи между } \\
\text { ними }\end{array}$ & $\begin{array}{l}\text { Философия. } \\
\text { Введение в научные } \\
\text { исследования. } \\
\text { Теория систем и } \\
\text { системный анализ и др. }\end{array}$ & $\begin{array}{l}\text { Знает: } \\
\text { - сущность системного подхода к анализу } \\
\text { объектов исследования; } \\
\text { - процедуры системного анализа, } \\
\text { включающего методики проведения } \\
\text { исследования и организацию процесса } \\
\text { принятия решения; } \\
\text {-основные философские идеи и категории в } \\
\text { их историческом развитии и социально- } \\
\text { культурном аспекте; } \\
\text { - принципы научного познания; } \\
\text { - сущность системного подхода к анализу } \\
\text { объектов исследования; } \\
\text { - основные положения, теоретические и } \\
\text { методологические принципы логики; } \\
\text { - методы логического анализа, методы } \\
\text { различного рода рассуждений }\end{array}$ \\
\hline
\end{tabular}

4. Опосредованно-прикладные связи формируются тогда, когда теория одной дисциплины помогает усвоить теорию другой дисциплины, причем формирование компетенций обучающихся происходит на основе изучения нескольких дисциплин, которые в отдельности не могут сформировать компетенции обучающихся.

Реализация типов связей тесно связана с функциями междисциплинарных связей. Перечислим их.

Методологическая функция направлена на то, чтобы у обучающихся на основе междисциплинарных связей формировались диалектикоматериалистическое мировоззрение, современные взгляды на развитие природы и общества. Есть мнение ученых, что связь человека с познаваемым миром может осуществляться на уровне общих сфер: В.И. Вернадский считает, что связь осуществляется на уровне биосферы, П.А. Флоренский - на уровне ноосферы, внедрение междисциплинарных связей - на уровне инфосферы.

Обучающее-образовательная функция направлена на то, чтобы формировать у обучающихся системные, глубокие, осознанные, гибкие знания. 
Междисциплинарные связи выступают здесь как средство изучения, усвоения, познания и установления связей между терминологией, формируемой содержанием нескольких дисциплин.

Интегрирующе-дифференцирующая функция направлена на взаимодействие содержания различных дисциплин, взаимообмен информацией и умение эту информацию дифференцировать и умело ею пользоваться.

Развивающая функция способствует формированию системного и творческого мышления обучающихся, формирует у них познавательную активность, самостоятельность и интерес к познанию дисциплин, что, по мнению Л.С. Выготского, позволяет определить обучающимся «зону актуального развития». Междисциплинарные связи помогают обучающимся наметить собственную «зону ближайшего развития» (по Л.С. Выготскому), преодолеть барьер между содержанием нескольких дисциплин и иллюстрировать знания одной дисциплины при изучении другой.

Конструктивная функция совершенствует содержание учебного материала. Для ее реализации используются определенные методы и формы организации обучения, а внедрение междисциплинарных связей требует разработки рабочих программ дисциплин с учетом содержания других учебных дисциплин.

Систематизирующая функция направлена на соблюдение четкого временного планирования изучаемого материала и связи его с последующим и предшествующим материалом не только в отдельной дисциплине, но и в междисциплинарной связи с материалом других модулей.

Реализация перечисленных функций строится с учетом определенных принципов междисциплинарных связей. Перечислим связи:

1. Принциип сочетания комплексных, междисииплинарных и частных дидактических иелей. При реализации дидактической системы междисциплинарных связей реализуются частные цели отдельных дисциплин, которые соответствуют целям других дисциплин учебного плана.

2. Принции интеграџии элементов системы. При построении системы обучения с применением междисциплинарных связей содержательные элементы являются относительно самостоятельными единицами учебного процесса, однако объединенные общей целью дают такое свойство, которым не обладает ни один элемент в отдельности.

3. Принции конвергентности. Совпадение содержания знаний по нескольким дисциплинам требует умения мыслить глобально и оценивать 
информацию на основе системной сущности всех явлений и процессов, что способствует глубокому изучению нескольких дисциплин одновременно.

4.Принцип системности и последовательности. При внедрении междисциплинарных связей необходимо учитывать доступность и привлекательность информации, выделение существенных аспектов изучаемого материала и акцентирование на них внимания.

5. Принциип реализаџии обратной связи. При построении системы обучения с применением междисциплинарных связей необходимо предусматривать критерии и уровни оценки эффективности внедрения.

6. Принцип эмерджентности. На основе междисциплинарных связей формируются совершенно новые знания, которые не могут быть сформированы отдельно взятой дисциплиной.

7.Принщип оптимального предоставления информаџионного $и$ методического материала. При построении системы обучения с применением междисциплинарных связей необходимо определить пути оптимальной реализации процесса, построенного на единстве информационного поля основ всех наук и с использованием единого методического обеспечения, что практически поможет обучающимся увидеть взаимосвязь законов, правил, систем.

8. Принцип смысловых поворотов. Смысловые повороты позволяют обобщить знания по дисциплинам, обозначить взаимодействие одной дисциплины с другими, представить реальный вклад каждой дисциплины в раскрытие содержательной линии, отраженной в стандартах образования.

Междисциплинарные связи можно представить в виде классификации.

1. Междисииплинарные связи по составу.

Состав междисциплинарных связей определяется содержанием учебного материала, формируемыми знаниями, умениями, владениями и мыслительными операциями, поэтому по составу выделяют типы междисциплинарных связей:

- содержательные связи реализуются разными способами. Первый способ: междисциплинарная информация используется только при изучении темы базового учебного предмета (прямые связи). Второй способ: изучаемая тема является «поставщиком» информации для других тем, других дисциплин учебного плана вуза (обратные или восстановительные связи). Содержательные связи реализуются через факты, понятия, законы, теории, методы наук;

- операционные связи реализуются через формируемые навыки, умения, владения, мыслительные операции и способы мышления; 
- методические связи реализуются через использование одних и тех же методов, приемов, форм, технологий на разных дисциплинах;

- организационные связи реализуются через определенные формы и способы организации учебно-воспитательного процесса, через модели организации образовательного процесса, чтобы установить уровень реализации процесса с применением МДС.

2. Междисциилинарныле связи по направлению:

- односторонние, т.е. междисциплинарная информация одного, двух или нескольких дисциплин используется для конкретно рассматриваемой одной учебной темы (прямые связи);

- двусторонние, т.е. междисциплинарная информация для конкретной темы является не только основой для усвоения этой дисциплины, но также усвоенная информация становится «поставщиком» информации для дисциплины, которая сама была «поставщиком» информации, т.е. идет взаимное обогащение дисциплин (обратные, или восстановительные связи);

- многосторонние, т.е. междисциплинарная информация одной дисциплины становится «поставщиком» информации для другой дисциплины, а информация, полученная на другой дисциплине, становится «поставщиком» информации для третьей дисциплины (прямые и обратные связи).

3. Междисииплинарные связи по временному способу:

- какие знания обучающимися уже получены, а какие еще предстоит усвоить (хронологические связи);

- какая тема является предшествующей, а какая последующей (хронологические синхронные связи);

- сколько времени необходимо для изучения содержания дисциплин в процессе осуществления междисциплинарных связей.

По временному фактору выделяют типы междисциплинарных связей:

- хронологические. Это связи последовательности их осуществления, которые делятся на преемственные, синхронные $u$ перспективные. Из хронологических видов преобладают преемственные и перспективные виды связей, тогда как синхронные резко ограничены, а во внутридисциплинарных связях синхронный вид вообще отсутствует;

- хронометрические. Это связи по продолжительности взаимодействия элементов, которые делятся на локальнье, среднедействующие, длительно действующчие. 
Перечисленные междисциплинарные связи наглядно представлены в таблице 2 .

\section{Таблица 2}

\section{Классификация междисциплинарных связей}

\begin{tabular}{|c|c|c|}
\hline $\begin{array}{c}\text { Формы } \\
\text { междисциплинарных } \\
\text { связей }\end{array}$ & $\begin{array}{c}\text { Типы междисциплинарных } \\
\text { связей }\end{array}$ & $\begin{array}{c}\text { Виды междисциплинарных связей } \\
\text { (по В.Н. Максимовой [4] и нашими } \\
\text { добавлениями) }\end{array}$ \\
\hline \multirow[t]{4}{*}{ 1. По составу } & 1. Содержательные & $\begin{array}{l}\text { 1. Содержательно-информационные: } \\
\text { 1.1. Фактические. } \\
\text { 1.2. Понятийные. } \\
\text { 1.3.Теоретические (философские, } \\
\text { идеологические, методологические) }\end{array}$ \\
\hline & 2. Операционные & $\begin{array}{l}\text { 2. Операционно-деятельностные: } \\
\text { 2.1. Мыслительные операции. } \\
\text { 2.2. Формы, виды, способы мышления } \\
\text { 2.3. Формируемые компетенции }\end{array}$ \\
\hline & 3. Методические & $\begin{array}{l}\text { 3. Организационно-методические: } \\
\text { 3.1. Формы организации обучения. } \\
\text { 3.2. Методы и приемы обучения. } \\
\text { 3.3. Технологии обучения }\end{array}$ \\
\hline & 4. Организационные & $\begin{array}{l}\text { 1. Модель содержания образования с } \\
\text { МДС. } \\
\text { 2. Модель организационно- } \\
\text { управленческого процесса с МДС. } \\
\text { 3. Модель практической реализации } \\
\text { образовательного процесса с МДС. } \\
\text { 4. Модель результативности } \\
\text { образовательного процесса с МДС }\end{array}$ \\
\hline \multirow[t]{3}{*}{ 2. По направлению } & 1. Односторонние & \\
\hline & 2. Двусторонние & \\
\hline & 3. Многосторонние & \\
\hline \multirow[t]{2}{*}{$\begin{array}{l}\text { 3. По временному } \\
\text { способу }\end{array}$} & $\begin{array}{l}\text { 1. Хронологические: } \\
\text { 1.1. Преемственные } \\
\text { 1.2. Синхронные } \\
\text { 1.3. Перспективные }\end{array}$ & \\
\hline & $\begin{array}{l}\text { 2.Хронометрические: } \\
\text { 2.1. Локальные. } \\
\text { 2.2. Среднедействующее. } \\
\text { 2.3. Длительно действующие }\end{array}$ & \\
\hline
\end{tabular}


Используя эту классификацию, можно установить связи дисциплин внутри модуля, а также внутридисциплинарные связи учебного плана в целом.

Дадим характеристику видам междисциплинарных связей и определим, как они формируют компетенции обучающихся.

Виды междисциплинарных связей.

1. Содержательно - информационные междисциплинарные связи.

1.1. Фактические связи. Междисциплинарные связи на уровне фактов это установление родства изучаемых в разных учебных дисциплинах фактов, которые подтверждают, раскрывают общие идеи и теории разных наук. Обучающиеся запоминают факты из одной дисциплины и приводят их в качестве примера на другой дисциплине. В результате такого процесса у обучающихся:

- формируются процессы запоминания;

- актуализируется фактический материал;

- переносятся и обобщаются знания по разным дисциплинам;

- совершаются мыслительные процессы.

1.2. Понятийные связи. Проблеме формирования понятий обучающихся на основе междисциплинарных связей посвящены исследования Ф.П. Соколовой [5], где доказывается, что в результате такого процесса у обучающихся:

- расширяются, углубляются знания о признаках предметных понятий, что помогает формулировать общие для родственных дисциплин понятия;

- формируются общие дисциплинарные умения сравнивать, конкретизировать, обобщать, формулировать определения, объяснять факты;

- качественно преобразуются способы познавательной деятельности.

1.3. Теоретические связи способствуют взаимосвязи теорий различных дисциплин и дают основания для формулирования новых теорий, которые не свойственны отдельным предметам.

Например, междисциплинарные теоретические философские связи. На основе общих положений материалистической философии выявляются сходные линии развития специальных знаний и складывается стройная система научно - философской картины мира.

Междисциплинарные теоретические экономические связи - это синтез знаний, включенных в содержание дисциплин разных модулей, например по основам экономики, менеджмента, маркетинга, управления персоналом, управления экономикой организации и т.д. 


\section{Междисциплинарные теоретические}

порождают методологические знания о процессах целеполагания, планирования, прогнозирования, контроля, коррекции, оценки, которые формируются именно на основе междисциплинарных связей.

\section{2. Операциионо-деятельностные междисциилинарные связи.}

\section{1. Мыслительные операции.}

Под мыслительными операциями понимается интенсивная, напряженная деятельность обучающихся, которая проявляется в процессах анализа, синтеза, сравнения, абстрагирования, обобщения, конкретизации, классификации и т. д.

2.2. Формыл, виды, способы мылиления.

Содержание мышления обучающихся проявляется через формы (понятия, суждения, умозаключения), виды (теоретико-понятийное, нагляднодейственное, образное, отвлеченное) и способы (индукция и дедукция) деятельности.

\section{3. Формируемые компетенции.}

В ходе практической деятельности формируются компетенции обучающихся:

- умеют анализировать окружающую действительность;

- вырабатывают собственные взгляды на изучаемые процессы;

- испытывают недостаток теоретических знаний;

- формируют желание дополнительного познания.

Отсюда, связь теоретического обучения должна сочетаться с практической деятельностью обучающихся, но пути взаимодействия могут быть различными, например:

- на теоретических занятиях используются практические сведения, факты для получения обобщений, выводов;

- применяются теоретические положения и закономерности для выполнения практических работ;

- организуются самостоятельные наблюдения на практических занятиях, полученные результаты используются на теоретических занятиях;

- проводятся экскурсии на предприятия для ознакомления с технологическим процессом и условиями труда; полученные материалы используются на теоретических и практических занятиях;

- формируются навыки работы с научной и справочной литературой, совершенствуется речь. 
3. Организационно-методические междисциплинарные связи.

Реализация данных связей возможна при использовании различных форм, методов, приемов обучения и соблюдении дидактических требований к ним.

О них следует поговорить отдельно.

\section{3. Вариативные междисциплинарные формы, методы и приемы обучения}

\section{1. Формы внедрения междисциплинарных связей}

Применение междисциплинарных связей в практической деятельности стало основой появление новых форм организации учебного процесса:

1) лекция с междисциплинарными связями строится на сочетании информации дисциплин одного или нескольких модулей;

2) комплексньй семинар позволяет обобщать знания обучающихся из разных модулей с позиций мировоззренческих идей и успешно решать в единстве задачи формирования знаний, умений и владений. Такие семинары являются действенным средством реализации комплексного подхода к обучению;

3) комплексные экскурсии способствуют формированию компетенций обучающихся и направлены на закрепление и углубление знаний при изучении междисциплинарных дисциплин, получению практической информации, расширению объема жизненных наблюдений и кругозора, умению переносить теоретические знания на практику.

4) междисциплинарные научно-практические конференции формируют компетенции обучающихся самостоятельно организовывать поиск информации по теме конференции, пользоваться несколькими источниками, анализировать, сопоставлять факты и явления из разных источников, самостоятельно оценивать прочитанное, делать выводы и обобщения, проявлять навыки самостоятельного рецензирования статьи, демонстрировать на практике монологическую, диалогическую и письменную речь;

5) комплексные факультативы базируются на материале нескольких дисциплин, что позволяет обучающимся хорошо усваивать программу и видеть единую картину мира, которая изучается в каждой дисциплине обособленно;

6) деловая игра развивает творческое мышление и самопознание, меняет мотивацию обучения, развивает инициативные формы познания, поэтому цели деловых игр можно обозначить, как овладение междисциплинарными 
компетенциями, социальным опытом, поиск новых или отработка и совершенствование известных приемов той или иной деятельности;

7) коллоквиум направлен на выяснение степени усвоения материала обучающимися на основе междисциплинарных связей и снятия возникающих проблем, а также является стимулом к систематическому усвоению знаний по всем дисциплинам учебного плана.

Реализация различных форм организации обучения с использованием МДС способствует реализации принципа сочетания комплексных и частных дидактических целей и учитывает методы внедрения междисциплинарных связей.

\section{2. Методы и приемы внедрения междисциплинарных связей}

Особую роль в передаче и усвоении знаний получают методы внедрения междисциплинарных связей.

Методы обучения с применением междисциплинарных связей - это способ упорядоченной взаимосвязанной деятельности преподавателей разных дисчиплин и обучающихся, направленный на формирование интегральных компетенций [определение наше - Н.Попова].

Основными условиями внедрения методов с применением междисциплинарных связей являются:

1. Включение в объяснение нового материала об изучаемом объекте знаний, полученных по другим дисциплинам.

2. Применение наглядных пособий с междисциплинарным содержанием.

3. Приведение примеров из изучаемой дисциплины при освоении последующих дисциплин.

4. Использование комплексных заданий для выполнения самостоятельных работ на обоснование, обобщение, конкретизацию, сравнение, синтез знаний по смежным учебным дисциплинам.

5. Задания на иллюстрацию знаний одних дисциплин при помощи знаний по другим дисциплинам.

6. Выполнение проектов на демонстрацию междисциплинарных связей.

В практической деятельности используются когнитивные и креативные методы обучения.

Когнитивные методы обучения направлены на познание обучающимися основ отдельных наук, что приводит к осознанию общей картины мира. Перечислим основные из них [6, с.323-325]. 
Метод эмпатии. Это умение выполнять роли других людей. Например, во время деловой игры студенты становятся руководителями организации, заместителями руководителя, наемными рабочими и т.д. Этот метод развивает способность мыслить, рассуждать, включать чувства и т.д.

Метод символического видения - это отыскивание связей между объектом и его символами.

Метод эвристических вопросов. Для отыскивания сведений о предмете необходимо задать 7 ключевых вопросов: Кто? Что? Зачем? Где? Чем? Как? Когда?

Метод сравнения используется для изучения явления. Обучающиеся задают себе вопросы: Что значит сравнить? Все ли можно сравнить? Зачем сравнивать?

Метод эвристического наблюдения применяется при формировании теоретических знаний. Обучающиеся наблюдают за объектом под руководством преподавателя либо самостоятельно.

Метод исследований. После выбора объекта исследования обучающиеся самостоятельно изучают его по плану: цель исследования - план работы - факты об объекте - рисунки - возникшие вопросы и проблемы - версии ответов гипотезы - суждения - осознанные способы деятельности - результаты и выводы.

Метод конструирования понятий. Сначала обучающиеся конструируют формулировку изучаемого понятия самостоятельно. Формулировка записывается. Затем обучающиеся знакомятся с трактовкой этого понятия различными учеными и сопоставляют с первоначальной формулировкой.

Метод конструирования правил. Формулировки понятий могут быть созданы, «открыты» самими обучающимися.

Метод гипотез. Обучающиеся формулируют возможные решения поставленной задачи и доказывают, какая из гипотез реалистичнее.

Метод прогнозирования применяется к реальному или планируемому процессу. Например, предлагается исследовать динамику изменений семейного бюджета за месяц. Обучающиеся делают наблюдения, ведут ежедневные записи: сколько денег поступило в семейный бюджет, на что потрачены деньги. Через месяц прогноз сравнивается с реальностью, обсуждаются результаты, делаются выводы [7, с.94].

Метод ошибок. Обучающимся даются задания с заведомыми ошибками. Поиск ошибок становится источником новых знаний, развивает эвристическую деятельность, инсайт. 
Метод конструирования теорий. Системное изучение проблемы позволяет обучающимся обнаружить лакуны в теории и на основе сопоставлений самостоятельно сформулировать определение по теории изученного материала.

Креативные методы обучения способствуют развитию фантазии обучающихся и позволяют создавать индивидуальные проекты. Перечислим основные из них.

Метод придумывания. Для регулирования умственных способностей используются приемы: а) замещение качества одного объекта качествами другого с целью создания нового объекта; б) отыскивание свойств предмета в другой среде; в) изменение элемента изучаемого объекта и описание свойств нового, измененного объекта.

Метод «Если был...». Используя этот метод, предлагается составить описание или нарисовать картину о том, что произойдет, если бы...Этот метод помогает развивать творческие способности, воображение и умение доказательно формулировать свою речь.

Метод образной картиньl. При изучении теории объект изучается по частям, но частные закономерности необходимо объединить в целое, поэтому обучающиеся самостоятельно создают обобщенную образную картину, на которой могут быть слова, картинки, стрелки, что становится своеобразной ментальной картой.

Метод гиперболизации. При использовании этого метода уменьшается или увеличивается объект познания. Придумывается, например, самый короткий термин (иск, лаг, лот, ярд) и самый длинный (гратификация, дезинтермедиация, капиталовложения, коммуникабельность) [7, с.94].

Составной частью метода являются приемы, которые условно можно разделить на:

1. Приемы, активизирующие психические свойства обучающихся (мышление, внимание, память, восприятие, воображение и другие).

2. Приемы, активизирующие переживания, вызывающие чувства, связанные с изучаемым материалом.

3. Приемы контроля, самоконтроля и самообучения.

4. Приемы управления учебным процессом через коллективные и личностные взаимоотношения с обучающимися.

Отдельные приемы обучения с междисциплинарными связями могут входить в состав методов обучения. В зависимости от ситуации приемы могут 164 
играть роль полноценного метода, а метод может стать отдельным приемом в рамках другого, более емкого метода [7, с.85]. Для реализации междисциплинарных связей основными становятся следующие методические приемы: мысли во времени, снежный ком, идейная карусель, рынок мнений, сопоставление, ассоциации и др. [8].

Технология внедрения приемов междисциплинарных связей:

Включение в объяснение нового материала фактов из других дисциплин.

Постановка проблемных вопросов и беседа на воспроизведение знаний из других дисциплин.

Выполнение письменной работы, которую разрабатывают преподаватели нескольких дисциплин и оценивают каждый свой раздел.

Выполнение заданий по разным дисциплинам, направленным на решение одной общей проблемы.

Решение кроссвордов, буквоградов междисциплинарного характера.

Домашнее задание с применением знаний из других дисциплин.

\section{3. Технологии обучения.}

Внедрение МДС при формировании компетенций обучающихся может быть осуществлено на основе различных технологий обучения: например, технологии SMART, проблемного обучения, на основе эффективности управления и организации учебного процесса, уровневой дифференциации, индивидуализации обучения, дистанционного обучения, дидактического усовершенствования и конструирования материала, авторских и альтернативных технологий, технологии критического мышления, информационно-коммуникативной технологии, проектной технологии, кейстехнологии, технологии творческих мастерских, модульного обучения и т.д.

Отсюда, при установлении и реализации междисциплинарных связей при формировании компетенций обучающихся необходимо:

1. Четко формулировать цель занятия и устанавливать формируемые компетенции на основе ФГОС $3++$.

2. Обеспечивать активность обучающихся по применению знаний из других дисциплин.

3. Объяснять причинно-следственные связи, сущности изучаемых явлений и процессов.

4. Формировать навык обобщения изученного материала в разных дисциплинах. 
5. При завершении занятия формулировать выводы мировоззренческого, обобщенного характера, которые опираются на связь знаний из разных дисциплин.

\section{4. Модель содержания образования с междисциплинарными связями}

Выбор учебных дисциплин, основанных на сочетании междисциплинарности, дает возможность построить учебный процесс с учетом способностей и интересов обучающихся и обеспечить дифференциацию образования. С учетом дифференциации можно выделить три модели содержания междисциплинарных связей:

1) дисциплины, обязательные для изучения, + дисциплины для углубленного изучения;

2) дисциплины, обязательные для изучения, + факультативные курсы;

3) дисциплины, обязательные для изучения, + дисциплины для углубленного изучения + факультативные курсы.

Как в вузе осуществить этот процесс наилучшим образом?

Реализации модели содержания с применением МДС будет способствовать рабочая программа дисциплины, которая может рабочей и авторской.

Рабочие программы дисциплин отражают требования ФГОС, а также возможности конкретного вуза и утверждаются методическим советом.

Авторские программы дисциплин, учитывая требования ФГОС, могут содержать иную логику построения учебного процесса, собственные подходы автора к рассмотрению теорий, явлений, поэтому программы обязательно проходят процедуру рецензирования и утверждаются на методическом совете вуза или кафедры.

Программа изложения учебного материала с использованием МДС может иметь линейную, концентрическую, спиральную и смешанную структуру.

При линейной структуре учебный материал с применением междисциплинарных связей образует непрерывную последовательность излагаемого материала, содержание дисциплины передается один раз.

Концентрическая структура изложения учебного материала предполагает возвращение к изученным знаниям. Один и тот же теоретический вопрос повторяется несколько раз на постоянно расширяющемся и углубленном уровне. 
Спиральная структура изложения учебного материала направлена на то, чтобы обучающиеся постоянно расширяли и углубляли круг знаний по определенной теме.

При смешанной структуре изложения учебного материала используется комбинация всех перечисленных способов.

Как в рабочей программе спланировать междисциплинарные связи?

В практике обучения сложились три основных способа планирования междисциплинарных связей: сетевое, предметное, тематическое.

Сетевое планирование - это форма выражения плана внедрения МДС. В сетевом графике отражены дисциплины, имеющие общие темы для изучения, и определено время их изучения. Содержание и основные направления осуществления междисциплинарных связей при сетевом планировании можно представить в виде следующей системы:

1. Основные направления в осуществлении междисииплинарных связей:

а) разработка тематического планирования;

б) составление графиков усвоения дисциплин;

в) группировка дисциплин в модулях.

2. Средства осуществления междисииплинарных связей:

a) разработка карточек - заданий;

б) изготовление наглядных пособий по междисциплинарным связям;

в) разработка комплексных заданий для выполнения проектов.

3. Формы осуществления междисциплинарных связей:

а) различные формы занятий;

б) факультативы технического творчества;

в) научно-практические конференции, проводимые по новым технологиям;

г) комплексные экскурсии и т.д.

Предметное планирование. Планирование междисциплинарных связей внутри учебной дисциплины осуществляется преподавателем, поэтому могут использоваться разные подходы к анализу междисциплинарных связей. Междисциплинарные связи рекомендуется использовать в сочетании с внутридисциплинарными связями. Наличие рабочей программы дисциплины позволяет заранее изучить необходимое для каждой последующей учебной темы содержание смежных дисциплин модуля, вовремя дать обучающимся домашнее задание на повторение опорных знаний из других дисциплин. Такое 
планирование позволяет успешно реализовать принцип обратной и конвергентной связи.

При использование предметного плана возможно заранее спланировать консультации и посещения лекций преподавателей других дисциплин, подобрать необходимую литературу для включения в свои лекции темы по междисциплинарным связям.

Тематическое планирование. $\mathrm{B}$ рабочей программе дисциплины учитывается логика подачи материала, устанавливаются тематические связи с другими дисциплинами. Составляя тематический план, преподаватель наглядно видит, для чего, с какой познавательной целью на отдельных лекциях необходимо использовать те или иные знания из других дисциплин. Это создает опору для введения новых понятий, объяснению причинно следственных связей в изучаемых явлениях, конкретизирует общие идеи или доказывает выводы, новые теоретические положения и т.п. Такое планирование позволяет успешно реализовать принцип эмерджентной связи.

Положительные стороны тематического планирования:

- формулируются цели и задачи занятия с учетом междисциплинарных связей;

- задаются конкретные вопросы, требующие воспроизведения и применения знаний нескольких дисциплин;

- развивается навык формулирования мировоззренческого вывода;

- задаются домашние задания междисциплинарного содержания и т.д.

Успешность планирования достигается, если получены необходимые сведения:

- в какой основной и дополнительной литературе содержится материал, имеющий отношение к данной теме;

- когда данный материал изучался в смежной дисциплине;

- краткое содержание материала смежной дисциплины.

Составляя рабочие программы дисциплин с использованием МДС преподавателю важно знать:

- что обучающиеся уже усвоили из необходимых опорных знаний на лекциях по другим дисциплинам;

- как установлены знания об объекте;

- каковы способы познания;

- зачем необходимо изучать данный объект. 
5. Модель

организационно-управленческого

процесса

c

\section{междисциплинарными связями}

Разработка теоретических основ модели организационноуправленческого процесса внедрения междисциплинарных связей строится на содержании дисциплин. Прежде, чем приступить к реализации модели, необходимо определить круг синтезированных тем всех учебных дисциплин, которые должны включать в себя наиболее значимые темы, способствующие раскрытию ведущих, основополагающих идей каждой дисциплины, иметь высокую степень обобщения и интеграции знаний в содержании каждой дисциплины.

После выявления общих тем нескольких дисциплин необходима проработка модели организация учебного процесса, который включает в себя междисциплинарные связи. Модель организации учебного процесса представляет собою систему взаимосвязанных модулей:

1) теоретический модуль. Для создания дидактической модели междисциплинарных связей в рабочей программе дисциплины проводят внутренний и внешний анализ содержания учебных дисциплин. Внутренний анализ - это структурно-логический анализ содержания дисциплины и выявление ведущих положений и основных связеобразующих элементов с другими дисциплинами. Внешний анализ - это структурно-логический анализ содержания тем дисциплины с другими дисциплинами учебного плана для определения степени «перекрываемости» их содержания с содержанием изучаемой дисциплины и выявление «опорных» междисциплинарных знаний, которые необходимо использовать, чтобы научно и всесторонне раскрыть ведущие положения изучаемой дисциплины;

2) практический модуль предполагает разработку пособия для обучающихся, сборника задач и упражнений, комплекс лабораторноисследовательских работ, проектных заданий, тестов междисциплинарного содержания;

3) методический модуль включает в себя методические рекомендации для преподавателей и обучающихся по реализации теоретического и практического модуля;

4) методологический модуль включает в себя серию материалов: тезисы, статьи, монографии с научным обоснованием рассматриваемой проблемы.

Чтобы модель междисциплинарных связей работала, необходимо учитывать системные связи при организации модели: 
1. Организационные связи:

- связи планирования;

- связи организации исполнения;

- связи самоконтроля за исполнением.

2. Содержательно-информационные связи:

- фактологические,

- понятийные,

- теоретические.

3. Синхронные многодисциплинарные связи. Перенос знаний из одной области науки в другие убеждает обучающихся в том, что сила научного знания не только в логическом построении какой-либо его отдельной области, но и в универсальности, всеобщности фундаментальных положений науки.

4. Асинхронные связи. Они характеризуют временные связи между учебными дисциплинами, которые необходимо осуществлять так, чтобы не нарушать логической структуры какой-либо из них, поэтому междисциплинарные связи должны быть взаимными. Из этого следует, что в ряде случаев полезно провести пропедевтическое изучение некоторых «несинхронизирующихся» понятий в смежной учебной дисциплине.

5. Понятийные связи учитываются при разработке учебных программ, планов, учебников, а также в практике преподавания.

6. Идейные связи. Рассматривается согласование и взаимодополнение одних и тех же фактов, понятий, законов и теорий в различных учебных дисциплинах на основе общих идей, концепций и принципов.

7. Связи по методам науки обозначают, что при изучении отдельных дисциплин есть специфические методы изучения каждой науки, поэтому при междисциплинарных связях необходимо использовать методы смежных наук.

8. Системно-синтетические связи учебных дисииплин достигаются при реализации обзорных и обобщающих лекциях по отдельным дисциплинам, а также лекциями по циклам учебных дисциплин, принадлежащих к одному модулю.

Соблюдение перечисленных связей даст основание для установления уровней организации учебного процесса. Выделяются следующие уровни организации учебного процесса на основе междисциплинарных связей:

- лекционный - обобщающие лекции, учебные темы;

- тематический - вся система занятий учебной темы подчиняется решению крупной междисциплинарной проблемы - связи с другими дисциплинами; 
- $\quad$ сквозной - система занятий, которые охватывают несколько учебных тем разных дисциплин;

- внутрицикловой - изучается одна и та же тема в разных дисциплинах;

- межиикловой - разные дисциплины имеют общие темы, поэтому содержательно дополняют друг друга.

\section{6. Модель практической реализации образовательного процесса с} междисциплинарными связями

Практическая реализация модели с применением междисциплинарных связей тесно сопряжена с методикой, которая имеет три ступени.

На первой ступени (условно названной воспроизводящей) основная цель преподавателя - научить использовать знания, полученные на других дисциплинах. Эта ступень может быть разбита на три этапа.

1 этап. Организация прощесса повторения необходимых сведений из других дисциплин.

2 этап. Объяснение нового материала с использованием фактов и понятий из одной учебной дисииплины для подтверждения рассматриваемых теоретических положений в другой дисциплине.

3 этап. Изложение нового материала, который использует теории, факты из нескольких смежных дисциплин для объяснения рассматриваемых явлений.

На второй ступени (перенос знаний из одной дисцуиплинь в другую) основная цель - научить самостоятельно применять сведения из родственных дисциплин. Эта ступень тоже может быть разбита на три этапа.

На 1-ом этапе преподаватель просит обучающихся самостоятельного воспроизведения отдельных знаний фактического или теоретического характера из смежных дисииплин, что способствует выработке навыка применять знания в новой учебной ситуации и преодолевать психологический барьер.

На 2-ом этапе преподаватель требует уже не воспроизведения знаний, а демонстрацию знаний по другим дисциплинам для формирования понятий изучаемой дисциплины.

На 3-ем этапе от обучающихся требуется самостоятельное привлечение какой-либо теории, изученной на одной дисциплине, для объяснения изучаемых явлений на другой дисциплине. 
На третьей ступени (обобщающей) основная цель - научить самостоятельно применять понятия, факты, законы и теории для иллюстрации единства мира, объяснять общие законы диалектики.

\section{Модель результативности образовательного процесса с междисциплинарными связями}

Грамотно составленная модель образовательного процесса с применением междисциплинарных связей может дать определенные результаты.

Положительные результаты внедрения междисциплинарных связей заключаются в том, что увеличивается вероятность определения связей, их время включения в учебный процесс, а реализуемая модель позволяет развивать познавательные, исследовательские способности обучающихся, целенаправленно формировать их компетенции.

Несмотря на достаточное количество положительных моментов в реализации междисциплинарных связей, следует предусмотреть их отрицательное воздействие на учебный процесс.

Отрицательные результаты внедрения междисциплинарных связей могут проявляться в несогласованности терминов различных дисциплин, в игнорировании понятий, сформированных на других дисциплинах, не учитывается общая эффективность обучения по формированию компетенций и т.д. Проблема преодоления отрицательных воздействий внедрения междисциплинарных связей в учебный процесс может быть решена на уровня преподавателя.

Роль преподавателя в организации междисииплинарных связей

Обучение - двусторонний процесс, но деятельность преподавателя и студента неодинаковы. Преподаватель передает знания и показывает, как можно использовать междисциплинарные связи для приобретения новых знаний.

Преподаватель должен:

знать модели разработки рабочих учебных дисциплин с применением МДС, принципы, структуру, классификацию, виды, формы, методы, технологии реализации междисциплинарных связей;

уметь:

разрабатывать рабочие учебные дисциплины с применением МДС, 
реализовывать формы и методы междисциплинарных связей;

- использовать междисциплинарные связи в совершенствовании мировоззрения обучающихся и формировании компетенций;

владеть: МдС,

1) навыками разработки рабочих учебных дисциплин с применением

2) формами, методами, приемами, технологиями, способствующими реализации междисциплинарных связей;

3) навыками ведения педагогического исследования.

В результате внедрения рабочих учебных дисциплин с применением МДС, использования методики с применением МДС у обучающихся формируются следующие междисииплинарные компетенции:

1) самостоятельный перенос теоретических знаний из других дисциплин для расширения понимания теории, изучаемой в данной дисциплине;

2) умение привлекать теории, изученные на других дисциплинах, для объяснения фактов, рассматриваемых в данной дисциплине;

3) использование нового способа привлечения практических умений и навыков, полученных на занятиях родственных дисциплин, для получения новых экспериментальных данных;

4) овладение навыками диалогового решения задач, требующих комплексного применения знаний;

5) формирование оценочно-эмоционального отношения к миру и владение новым типом мышления - теоретическим, интегративным, синтетическим и т.д.

Реализация рабочих учебных программ с междисциплинарными связями формирует индивидуальные стили учебной деятельности. Перечислим некоторые из них [9, С.535-536]: абстрактный - обучающийся мыслит на уровне концепций; аналитический - анализирует и разбивает целое на части; интуитивно-мыслительный - интересуется системами и моделями; независимый - легко отличает существенную информацию от несущественной; нелинейный - организует информацию нелинейным способом; синтетический интегрирует и строит целое из частей.

Этапы деятельности преподавателей и обучающихся на основе внедрения междисциплинарных связей можно представить в виде обобщенной таблицы 3. 
Таблица 3

\section{Этапы деятельности преподавателей и обучающихся с применением междисциплинарных связей}

\begin{tabular}{|c|c|c|}
\hline № ח/П & Преподаватель & Обучающиеся \\
\hline \multicolumn{3}{|c|}{ Первый (организационный) этап } \\
\hline 1. & $\begin{array}{l}\text { Включение преподавателей в активную } \\
\text { познавательную деятельность, } \\
\text { формирующую теоретические } \\
\text { междисциплинарные знания и } \\
\text { соответствующую им междисциплинарную } \\
\text { структуру знаний }\end{array}$ & $\begin{array}{l}\text { Включение обучающихся в деятельность } \\
\text { по изучению основных структурных } \\
\text { элементов системы научных знаний, } \\
\text { общих для многих наук: теорий, законов, } \\
\text { методов научного познания }\end{array}$ \\
\hline \multicolumn{3}{|c|}{ Второй (формирующий) этап: } \\
\hline 2. & $\begin{array}{l}\text { Владение преподавателем обобщенными } \\
\text { формами, методами, приемами, } \\
\text { технологиями, способствующими } \\
\text { реализации принципа междисциплинарных } \\
\text { связей в процессе преподавания } \\
\text { дисциплины в рамках системы } \\
\text { гностического обучения }\end{array}$ & $\begin{array}{l}\text { Осознание обучающимися } \\
\text { необходимости использования знаний из } \\
\text { родственных дисциплин в процессе их } \\
\text { изучения. Формирование компетенций, } \\
\text { которые выполняют функцию общего } \\
\text { метода гностического познания единства } \\
\text { окружающего мира }\end{array}$ \\
\hline \multicolumn{3}{|c|}{ Третий (моделирующий) этап: } \\
\hline 3. & $\begin{array}{l}\text { На основе сложившихся } \\
\text { междисциплинарных знаний и умений } \\
\text { преподаватель разрабатывает } \\
\text { междисциплинарную рабочую программу } \\
\text { дисциплины, определяет структуру } \\
\text { учебных знаний и формы реализации, } \\
\text { разрабатывает методику осуществления } \\
\text { междисциплинарных связей в } \\
\text { используемой им педагогической } \\
\text { технологии. } \\
\text { Преподаватель предоставляет } \\
\text { обучающимся средства, необходимые для } \\
\text { включения их в творческую } \\
\text { исследовательскую деятельность } \\
\text { междисциплинарного характера }\end{array}$ & $\begin{array}{l}\text { На данном этапе обучающиеся, } \\
\text { используя предложенные } \\
\text { преподавателем средства реализации } \\
\text { междисциплинарных связей, } \\
\text { осуществляют перенос знаний, } \\
\text { полученных в различных дисциплинах, в } \\
\text { изучаемый предмет. } \\
\text { Осуществляется перенос практических } \\
\text { умений и навыков. При изучении } \\
\text { материала обучающиеся моделируют } \\
\text { различные поисковые ситуации, владеют } \\
\text { методом диалога, ведут } \\
\text { исследовательскую деятельность } \\
\text { междисциплинарного характера }\end{array}$ \\
\hline
\end{tabular}

Степень успешности реализации модели с применением междисциплинарных связей устанавливается на основе параметров и уровней. Разделяя мнение А.И.Гурьева [10], предлагаем следующую модель определения уровней внедрения междисцииплинарных связей.

Первый уровень: эпизодический (на отдельных занятиях). 
Второй уровень: частично-системный (в системе отдельных занятий).

Третий уровень: системный (вся образовательная организация, или кафедра, или отдельный преподаватель работает по проблеме реализации МДС).

Третий уровень оптимальный и эффективный, так как представляет собою определенную систему, что не создает перегрузок обучающихся и способствует формированию у них естественнонаучного мировоззрения.

Результативность обучения на основе междисциплинарных связей определяется на основе следующих показателей:

1) грамотный перенос знаний из одной дисциплины в другую;

2) умение отбирать знания из разных дисциплин, обобщать их и делать самостоятельные выводы;

3) мотивация учебно-познавательной деятельности обучающихся на основе междисциплинарных связей;

4) осознанное использование междисциплинарных связей для познания окружающего мира.

Междисциплинарные связи позволяют успешно реализовать учебные задачи и сформировать компетенции обучающихся (Табл. 4).

Таблица 4

Междисциплинарные компетенции обучающихся

\begin{tabular}{|c|c|c|}
\hline \multicolumn{3}{|c|}{ Междисциплинарные компетенции } \\
\hline $\begin{array}{c}\text { Виды междисциплинарных } \\
\text { связей }\end{array}$ & $\begin{array}{c}\text { Междисциплинарные } \\
\text { познавательные задачи }\end{array}$ & $\begin{array}{c}\text { Междисциплинарные } \\
\text { компетенции }\end{array}$ \\
\hline $\begin{array}{l}\text { Фактические - установление } \\
\text { родства, аналогии фактов, } \\
\text { изучаемых в разных учебных } \\
\text { дисциплинах, их всестороннее } \\
\text { рассмотрение в целях } \\
\text { формирования в сознании } \\
\text { обучающихся целостной } \\
\text { модели факта }\end{array}$ & $\begin{array}{l}\text { Установление } \\
\text { междисциплинарной связи на } \\
\text { основе общности фактов из } \\
\text { разных дисциплин с целью } \\
\text { конкретизации изучаемого } \\
\text { материала, формирования } \\
\text { новых понятий, их объяснения } \\
\text { с позиций общих теорий и } \\
\text { принципов }\end{array}$ & $\begin{array}{l}\text { Способность устанавливать } \\
\text { общности фактов из разных } \\
\text { дисциплин, осуществлять } \\
\text { всесторонний анализ; } \\
\text { сопоставлять, обобщать, } \\
\text { объяснять изученное с позиций } \\
\text { общенаучных идей; связывать } \\
\text { обобщённые факты с } \\
\text { целостной моделью }\end{array}$ \\
\hline $\begin{array}{l}\text { Понятийные - поэтапное, } \\
\text { поэлементное расширение и } \\
\text { углубление связей между } \\
\text { конкретными признаками } \\
\text { понятий, общих для разных }\end{array}$ & $\begin{array}{l}\text { Установление связей между } \\
\text { понятиями из разных } \\
\text { дисциплин с целью их } \\
\text { конкретизации, обобщения, } \\
\text { формирования системы }\end{array}$ & $\begin{array}{l}\text { Способность устанавливать } \\
\text { связи между понятиями разных } \\
\text { дисциплин, конкретизировать, } \\
\text { объяснять процессы и явления } \\
\text { одной науки с помощью }\end{array}$ \\
\hline
\end{tabular}




\begin{tabular}{|c|c|c|}
\hline дисциплин & $\begin{array}{l}\text { понятий разной степени } \\
\text { обобщенности, их } \\
\text { соподчиненности и развития, } \\
\text { объяснения причинно - } \\
\text { следственных связей явлений }\end{array}$ & $\begin{array}{l}\text { понятий другой науки, делать } \\
\text { мировоззренческие выводы на } \\
\text { основе общих понятий }\end{array}$ \\
\hline $\begin{array}{l}\text { Tеоретические - поэлементное } \\
\text { приращение новых } \\
\text { компонентов общенаучных } \\
\text { теорий, получаемых на } \\
\text { занятиях по разным } \\
\text { дисциплинам с целью } \\
\text { осознания целостной } \\
\text { теоретической системы знаний }\end{array}$ & $\begin{array}{l}\text { Установление связей между } \\
\text { теориями разных наук, их } \\
\text { точек соприкосновения, связей } \\
\text { между структурными } \\
\text { компонентами общенаучных } \\
\text { теорий и методами их } \\
\text { познания; приведение } \\
\text { теоретических знаний в } \\
\text { систему }\end{array}$ & $\begin{array}{l}\text { Способность рассматривать } \\
\text { научные теории как частный } \\
\text { случай более общих теорий; } \\
\text { связывать структурные } \\
\text { элементы общенаучных теорий } \\
\text { в единое целое; на основе } \\
\text { теории одной науки объяснять } \\
\text { факты, изучаемые смежной с } \\
\text { ней наукой }\end{array}$ \\
\hline $\begin{array}{l}\text { Философские - осознанное } \\
\text { усвоение знаний об } \\
\text { объективных законах развития } \\
\text { природы, общества, познания } \\
\text { на основе обобщения } \\
\text { конкретно - предметных и } \\
\text { философских знаний, } \\
\text { получаемых при изучении } \\
\text { дисциплин разных модулей }\end{array}$ & $\begin{array}{l}\text { Установление связей между } \\
\text { конкретно - предметными и } \\
\text { философскими знаниями с } \\
\text { целью формирования научно - } \\
\text { философской картины мира; } \\
\text { установление связей между } \\
\text { научными понятиями и } \\
\text { философскими категориями }\end{array}$ & $\begin{array}{l}\text { Способность рассматривать } \\
\text { предметные факты, понятия, } \\
\text { теории, законы с позиций } \\
\text { всеобщих диалектических } \\
\text { законов и категорий; } \\
\text { проводить поэлементное } \\
\text { обобщение знаний из разных } \\
\text { дисциплин при раскрытии } \\
\text { наиболее общих признаков } \\
\text { понятий диалектики, давать } \\
\text { определение этим понятиям с } \\
\text { опорой на конкретно - } \\
\text { предметные знания }\end{array}$ \\
\hline $\begin{array}{l}\text { Идеологические - } \\
\text { поэлементное обобщение и } \\
\text { сознательное усвоение } \\
\text { аксиологических знаний, } \\
\text { получаемых при изучении } \\
\text { гуманитарных и } \\
\text { естественнонаучных } \\
\text { дисциплин в целях } \\
\text { формирования идейно - } \\
\text { нравственного сознания }\end{array}$ & $\begin{array}{l}\text { Усвоение связей между } \\
\text { элементами аксиологических } \\
\text { знаний, получаемых при } \\
\text { изучении разных учебных } \\
\text { дисциплин; раскрытие идейно } \\
\text { - политических и нравственно } \\
\text { - эстетических аспектов } \\
\text { научных знаний с опорой на } \\
\text { факты, понятия, идеи, образы }\end{array}$ & $\begin{array}{l}\text { Способность связать в общую } \\
\text { систему знания разных видов, } \\
\text { форм общественного сознания } \\
\text { и человеческой практики; } \\
\text { ориентироваться в } \\
\text { комплексных проблемах } \\
\text { современности с их } \\
\text { аксиологических сторон; } \\
\text { раскрывать точки } \\
\text { соприкосновения } \\
\text { гуманитарных и } \\
\text { естественнонаучных знаний }\end{array}$ \\
\hline
\end{tabular}

Надеемся, что перечисленные идеи внедрения междисциплинарных связей на основе предложенного алгоритма смогут внести существенный вклад в реализацию ФГОС ВО $3++$. 


\section{Список литературы}

1. ФГОС ВО 3++ [Электронный ресурс]: http:// fgosvo.ru/fgosvo/151/ 150/24 (дата обращения: 13.02.2021).

2. Гурьев А.И. Межпредметные связи в системе современного образования: монография / А.И. Гурьев; под ред. А.В. Усовой, А.В. Петрова. Барнаул : Изд-во Алт.гос. ун-та, 2002, - 213 с.

3. Кукушин В.С. Теория и методика обучения: учебное пособие / В.С. Кукушин. - Ростов-на-Дону: Изд-во Феникс, 2005. - 467 с.

4. Максимова В.Н. Межпредметные связи и совершенствование процесса обучения / В.Н. Максимова. - М.: Просвещение, 1984. - 143 с.

5. Соколова Ф.П. Влияние межпредметных связей на повышение научности знаний по физике учащихся VII класса : автореферат дис.на соискание ученой степени кандидата педагогических наук. М., 1973, - 24 с.

6. Хуторской А.В. Современная дидактика : учебник для вузов / А.В. Хуторской. - СПб: Питер, 2001. - 544 с.

7. Попова Н.Е. Теория и методика обучения экономике: учебное пособие для студентов вузов / Н.Е. Попова, А.А. Лобут. - 2-ое изд., перераб. и доп. ГОУ ВПО «Урал.гос.пед.ун-т», Екатеринбург, 2008. - 421 с.

8. Попова Н.Е. Приемы обучения экономике : учебно-методическое пособие для студентов вузов / Н.Е. Попова, А.А. Лобут [и др.].- ФГБОУ ВО «Урал.гос.пед. ун-т». - Екатеринбург, 2016. - 62 с.

9. Коджаспирова Г.М. Педагогика : учебник для академического бакалавриата / Г.М. Коджаспирова. - 4-е изд., перераб. и доп. - М.: Издательство Юрайт, 2015. - 719 с.

10. Гурьев А.И. Методологические основы построения и реализации дидактической системы межпредметных связей в курсе физики средней школы: автореф. дис. на соискание ученой степени доктора педагогических наук. Челябинск, 2002, - 36 с. 